
\title{
25 Research Soure \\ Antioxidant Stress and Anticancer of Peptide Chelate Selenium Element in vitro
}

\section{Xian Li}

Inner Mongolia Medical College Affiliated Hospital: The Affiliated Hospital of Inner Mongolia Medical University https://orcid.org/0000-0002-9107-5096

\section{Xianjue Wang}

Inner Mongolia Medical College Affiliated Hospital: The Affiliated Hospital of Inner Mongolia Medical University

\section{Gang Liu}

inner mongolia medical university

\section{Yanan Xu}

Inner Mongolia Medical University

\section{Xinlin Wu}

inner mongolia medical university

Ru Yi

Inner Mongolia Medical University

Feng Jin

Inner Mongolia Medical University

\section{Chula Sa}

Inner Mongolia Medical University

Xiulan Su ( $\nabla$ xlsu@hotmail.com )

Inner Mongolia Medical University

\section{Research article}

Keywords: anticancer bioactive peptides, selenium element, gastric cancer, antitumor agent

Posted Date: October 9th, 2020

DOl: https://doi.org/10.21203/rs.3.rs-88931/v1

License: (c) (i) This work is licensed under a Creative Commons Attribution 4.0 International License. Read Full License 


\section{Abstract}

This contribution reports a facile synthesis of anticancer bioactive peptides (ACBP) - functionalized selenium particles (ACBP-S-Se) with enhanced anticancer activities and a detailed mechanistic evaluation of its regulation of oxidative stress in vitro. Structural and chemical characterizations were proved by ultraviolet absorption spectrum (UV), Fourier transform infrared spectroscopy (FT-IR), X-ray photoelectron spectroscopy (XPS), Nuclear magnetic resonance carbon (13C NMR) and hydrogen spectra (H NMR), scanning electron microscope (SEM), energy dispersive X-ray spectrom (EDX) and inductively coupled plasma mass spectrometry (ICP-MS). The results show that ACBP are effectively sulfhydrylation modification with S-acetylmercaptosuccinic anhydride (SAMSA) via chemical absorption. After the polypeptide was modified by sulfhydrylation, there were many sulfhydryl groups on the molecule, and the sulfhydryl group was used as the binding site of Se. A panel of selected human cancer cell lines demonstrated high susceptibility toward ACBP-S-Se and displayed significantly reduced proliferative abilities. Finally, the results presented herein suggest bioactive peptide chelate selenium element effectively inhibited the proliferation of MKN-45 and MKN-74 cell in vitro, which in turns allowed the successful application of the ACBP-S-Se in highly complex human cell lines. The related the regulation of oxidative stress gene is $C D K N 1 A, C C N B 1, T X N$ and $M A P 3 K 5$, while $C D K N 1 A$ and $T X N$ have ability to protecting cells to reduce oxidative stress and promoting cell growth arrest. Therefore, the great potential exhibited by ACBP-S-Se could make them an ideal candidate as a chemotherapeutic agent for human cancers, especially for gastric cancer.

\section{Introduction}

Oxidative stress refers to the aberrant production of active substances including reactive oxygen species (ROS) and nitrogen free radicals under various stress stimuli, which leads to unbalanced physiological status or oxidative stress-related damage via oxidation-reduction reactions ${ }^{1}$. Rigorous studies have revealed that reactive oxygen species (ROS) generated by cells under oxidative stress (OS) are involved in gastric tumorigenesis ${ }^{2}$.

Previous studies have confirmed that ROS is an actuation factor in gastric carcinogenesis both in clinical studies and in mouse models in vivo. The dysregulation of ROS promotes tumorigenesis and the development of abnormalities due to its ability to increase aberrant cell proliferation, survival, and cell migration in vivo ${ }^{3}$. Meanwhile, the aberrant production of ROS also induces DNA damage, leading to genetic disease, tumorigenicity and subsequent tumor progression ${ }^{4}$. If the accumulation of ROS overwhelms the death threshold, cellular apoptosis levels significantly increase, which enhance the antitumor effects of ROS production ${ }^{5}$. Denicola et al. confirmed that ROS alleviate certain specific cancers and that the redox state in cells is an important factor for the subsequent tumor formation potential, so the redox states of cells are likely to be potential therapeutic targets of cancers ${ }^{6}$. Finally, reactive oxygen species (ROS) may contribute to the regulation of apoptosis. 
Selenium (Se), with a narrow range between deficiency and toxic effects ${ }^{7}$, is an important oligoelement and one of the most important trace elements in organisms ${ }^{8}$. Meanwhile, Se is a key component of the antioxidant system ${ }^{9}$, which makes an indelible contribution to human health. The chemical forms of Se regulate its diverse biological effects, toxicity and bioavailability, and supplementation with Se improves the redox system, promotes proper immune system function and has anticarcinogenic effects ${ }^{10}$. Se deficiency leads to heart disease, hypothyroidism and a weakened immune system, but excess exposure to Se results in gastrointestinal disturbances, hair and nail changes and neurologic manifestations ${ }^{11,12}$. The presence of Se enhances the functions of the immune system, improves the proliferation and biofunctions of immune system cells, and enhances the phagocytosis of immune system cells, thereby improving the body's immune function and fundamentally improving its ability to resist disease ${ }^{13,14}$. In addition, at higher concentrations, Se has pro-oxidant properties and is essential for the antioxidant activities involved in anticarcinogenic actions ${ }^{15}$. Meanwhile, Se inhibits hepatocyte necrosis and DNA damage by inhibiting CTX-induced oxidative stress ${ }^{16}$.

Previous studies have confirmed that Se is a promising therapy for cancer ${ }^{17,18}$ via the formation of an internal environment that inhibits cancer proliferation. After cancer operation, Se supplementation obviously controls cancer deterioration, reduces the toxicity and side effects of chemotherapy and radiotherapy, and helps anticancer drugs improve the curative effect ${ }^{19,20}$.

Furthermore, Se, as an essential component of selenocysteine-containing proteins, is involved in most aspects of cell biochemistry and functions ${ }^{21,22}$. Younis et al. reported that supplementation with insulin transferrin selenium (ITS) to semen extenders benefits the cryopreservation of chimpanzee (Pan troglodytes) spermatozoa ${ }^{23}$.

Selenoproteins are essential for life, and several selenoproteins have been characterized as antioxidant enzymes, protecting against damage caused by free radicals, as already stated ${ }^{24}$. Further studies on selenoprotein gene expression and cytokine content in the chicken thymus have shown that a significant decrease in the expression levels of selenoproteins could result in oxidative stress in chicken thymus ${ }^{25}$. In addition, Se-containing molecules exert antioxidant properties associated with tumor growth, metastasis, angiogenesis, and drug resistance ${ }^{26}$. One of the more exciting areas of research in drug design is the synthesis of so-called polypeptide selenium chelate, with the added advantage of cancer stem cell line inhibition and antioxidant activity ${ }^{27}$. Here, the anticancer bioactive peptide (ACBP) is a low-molecularweight active substance that was extracted from goat liver and was produced by the Clinical Medicine Research Center, the Affiliated Hospital at Inner Mongolia Medical University ${ }^{28}$. Our former studies found that ACBP has superior antineoplastic activities and inhibits tumor growth in nude mice with Dutch gallbladder carcinoma. It also increases the chemotherapeutic sensitizing effect and reduces the side effects associated with chemotherapy ${ }^{29}$. A series of nonnatural selenium-containing amino acid derivatives and peptides have been synthesized in a flexible and modular strategy to establish an antigastric cancer system for treating diseases ${ }^{30}$. On the other hand, selenocarbohydrates, selenoamino 
acids, and selenopeptides take part in the synthesis of a large number of biological compounds. However, the related oxidative stress genes and potential antitumor efficacy of the as-synthesized ACBP chelate selenium have not been previously demonstrated. Furthermore, the molecular mechanism of the antioxidant regulatory system of the peptide chelate selenium is very important to reveal the regularity of tumorigenesis and drug resistance.

Here, sulfhydrylation modifications of ACBP were performed with S-acetylmercaptosuccinic anhydride (SAMSA) via chemical absorption. After sulfhydrylation, there were many sulfhydryl groups on the molecule, and the binding site of Se was used to link the sulfhydryl group. The molecular mechanism of the antioxidant regulatory system and antitumor effect of ACBP-S-Se on tumor cell lines were investigated in vitro.

\section{Experimental Methods}

\subsection{Materials}

ACBP was provided by the Clinical Medicine Research Center, Affiliated Hospital of Inner Mongolia Medical University. S-acetylmercaptosuccinic anhydride (S-AMSA) and hydroxylamine hydrochloride were purchased from Sigma.

\subsection{Cell culture}

The normal human gastric cell line (GSE-1) and human gastric cancer cell lines (MKN-45 and MKN-74) were purchased from the Institute of Cell Biology of the Chinese Academy of Sciences (Shanghai, China). GSE-1 and MKN-74 cells were cultured in DMEM (10566-016, Invitrogen, Thermo Fisher Scientific, Shanghai, China) supplemented with $10 \%$ fetal bovine serum (FBS, 10091148, Gibco, Shanghai, China) and $100 \mathrm{U} / \mathrm{mL}$ penicillin and streptomycin (P/S) at $37^{\circ} \mathrm{C}$ in a humidified chamber containing $5 \% \mathrm{CO}_{2}$. MKN-45 cells were cultured in RPMI1640 growth medium (61870036, Invitrogen, Thermo Fisher Scientific, Shanghai, China) supplemented with $10 \% \mathrm{FBS}$ and $100 \mathrm{U} / \mathrm{mL} \mathrm{P} / \mathrm{S}$ at $37^{\circ} \mathrm{C}$ in a humidified chamber containing $5 \% \mathrm{CO}_{2}$.

\subsection{Synthesis of ACBP-S-Se}

MOPS (2.08 g) was dissolved in $\mathrm{ddH}_{2} \mathrm{O}(200 \mathrm{~mL})$ to prepare a 3-morpholine-propanesulfonic acid (MOPS)-buffered solution. ACBP (1.0 g) was dissolved in a MOPS solution with a pH of 7.4 to obtain the ACBP solution. S-AMSA was added to the ACBP solution and incubated for $2 \mathrm{~h}$, during which the $\mathrm{pH}$ was maintained at 7.4. Next, the sample was stored in nitrogen to avoid air oxidation products. Then, 0.05 $\mathrm{mol} / \mathrm{L}$ hydroxylamine hydrochloride was added for further reaction for $3 \mathrm{~h}$. After the isolation of the sulfhydrylated ACBP, purified ACBP-S was obtained by gel chromatography. Here, $0.66 \mathrm{~g}$ sodium selenite was added to the ACBP-S solutions for $6 \mathrm{~h}$ to obtain the raw product of ACBP-S-Se, and then gel chromatographic column purification was performed again to produce a pure ACBP-S-Se solution. 
After vacuum freeze drying the ACBP-S-Se solution, the ACBP-S-Se particles were obtained for chemical structure characterization.

\subsection{Physical and chemical property analyses}

\subsubsection{FT-IR spectroscopic analysis}

FT-IR spectra were recorded using a Nicolet FT-IR 5700 spectrophotometer (Thermo Fisher Scientific, Waltham, MA, USA) under ambient conditions. The characterization of the four components (ACBP and ACBP-S-Se) was performed, and the samples were triturated with $\mathrm{KBr}$ at a ratio of 1:100 and pressed to form pelleted samples for FT-IR spectroscopic analysis at $500-4000 \mathrm{~cm}^{-1}$.

\subsubsection{X-ray photoelectron spectroscopy (XPS)}

X-ray photoelectron spectroscopy (XPS; Thermo Fisher, ESCALAB 250Xi, USA) was used to determine the elemental composition of ACBP and ACBP-S-Se, for which full (pass energy, $100 \mathrm{eV}$ ) and high-resolution spectra (pass energy, $20 \mathrm{eV}$ ) were recorded.

\subsubsection{Particle morphology}

The particle morphology of the ACBP-S-Se particles was examined by scanning electron microscopy (SEM) and energy dispersive X-ray spectroscopy (EDX). ACBP-S-Se was carefully lyophilized to maintain the surface structure. ACBP-S-Se was mounted, sputter-coated with gold, and observed under a Hitachi S570 SEM microscope (Hitachi, Tokyo, Japan).

2.4.4 Carbon nuclear magnetic resonance (13C NMR) and hydrogen nuclear magnetic resonance $(\mathrm{H}$ NMR) spectra

$\mathrm{H}-\mathrm{NMR}$ and $13 \mathrm{C}$-NMR spectra were recorded in deuteroxide $\left(\mathrm{D}_{2} \mathrm{O}\right)$ at $17^{\circ} \mathrm{C}$ using a Bruker DRX 500 spectrometer. For each spectrum, approximately 1500 transients were collected using the following acquisition parameters: $3 \mathrm{~s}$ delays between pulses, $90^{\circ}$ pulse of $5.4 \mu \mathrm{s}$, and contact time of $1 \mathrm{~ms}$. Data were acquired and processed using Topspin 2.1 (Bruker, Rheinstetten, Germany).

\subsubsection{SDS-Polyacrylamide gel electrophoresis}

The molecular weights of ACBP, ACBP-S and ACBP-S-Se were analyzed by sodium dodecyl sulfate polyacrylamide gel electrophoresis (SDS-PAGE) using a 16\% separating gel and a $8 \%$ stacking gel according to previous studies ${ }^{31}$. The ACBP, ACBP-S and ACBP-S-Se powders were mixed in $0.1 \mathrm{M} \mathrm{Tris-HCl}$ buffer $(\mathrm{pH}=6.8)$ containing $5 \% \beta$-mercaptoethanol, $2 \%$ SDS, $0.02 \%$ bromophenol blue and $10 \%$ glycerin, with a sample concentration of $2 \mathrm{mg} / \mathrm{mL}$. The mixed solutions were heated at boiling temperature for 5 min, while $15 \mu \mathrm{L}$ of the prepared samples was injected into each well and then ran to the bottom of the gel at $100 \mathrm{~V}$. The gel was stained using the Coomassie Blue (R-250) staining method, and the molecular weight was determined by comparison with the MW standard markers (BIO-RAD) (MW 10.0 180.0 kDa). 
Images were analyzed by Image Lab software version 5.0 (2000 Alfred Nobel Drive, Bio-Rad Laboratories Inc., WDC, USA).

\subsubsection{ICP-MS}

The selenium content of ACBP-S-Se was determined by inductively coupled plasma mass spectrometry (ICP-MS, Agilent Technologies 7900ICP, Beijing Tai Chi Flying Co., Ltd.). After ignition, the tested elements and internal standard (10 bbp TuneA) were set up under standard model. The parameters were set up as follows: $\mathrm{H}_{2} / \mathrm{He}$ was used as a collision gas with a flow velocity of $5.5 \mathrm{~mL} / \mathrm{min}$, the Co sensitivity was adjusted to $20000 \mathrm{CPS} / \mathrm{ppb}$, the $U$ signal maximum was adjusted, and then the Se in ACBP-S-Se was measured. The amount of selenium bound to ACBP was determined by the following formula:

$\mathrm{n}_{\mathrm{Se}} / \mathrm{n}_{\mathrm{ACBP}}=\left(\mathrm{m}_{\mathrm{Se}} / \mathrm{M}_{\mathrm{Se}}\right) /\left(\mathrm{m}_{\mathrm{ACBP}} / \mathrm{M}_{\mathrm{ACBP}}\right)=\left(\mathrm{C}_{\mathrm{Se}} / \mathrm{M}_{\mathrm{Se}}\right) /\left(\mathrm{C}_{\mathrm{ACBP}} / \mathrm{M}_{\mathrm{ACBP}}\right)=1228 \mathrm{C}_{\mathrm{Se}} / \mathrm{C}_{\mathrm{ACBP}}$

where $\mathrm{C}_{\mathrm{Se}}$ is the concentration of Se determined by ICP-MS; $\mathrm{C}_{\mathrm{ACBP}}$ is the concentration of ACBP determined by spectrophotometry (Nanodrop 2000C, Thermo Scientific, and Singapore).

\subsection{Drug treatments}

Before drug treatments, three cell lines were preplated in 6-well culture dishes (Corning, China) at a density of $5 \times 10^{5}$ cells/well and randomly divided into the following groups based on the ACBP-S-Se supplement to the basic culture medium. When the cell confluence reached $70 \%$, drug treatment was carried out. The optimization of the ACBP-S-Se concentration applied in this study was performed according to our former studies of BAPT ${ }^{32}$.

\subsection{Cell proliferation}

The proliferation ability of MKN-45 cells or MKN-74 cells after ACBP-S-Se treatments was determined by the IncuCyte Live Cell Analysis System according to our previous studies. Briefly, MKN-45 and MKN-74 cells were inoculated into a 96 -well plate at a density of $5 \times 10^{3} /$ well and cultured for $24 \mathrm{~h}$. After ACBP-SSe treatment, the 96-well plates were placed in the designated location of the IncuCyte live cell workstation, and cell proliferation was recorded for $24 \mathrm{~h}$ at intervals of $2 \mathrm{~h}$. Here, for MKN-45 and MKN-74 cells, the control group was not treated with any additional ACBP-S-Se $(0 \mathrm{mg} / \mathrm{mL})$, while the experimental group was treated with different concentrations of ACBP-S-Se $(5 \mathrm{mg} / \mathrm{mL}, 10 \mathrm{mg} / \mathrm{mL}, 20 \mathrm{mg} / \mathrm{mL}, 40$ $\mathrm{mg} / \mathrm{mL}$ and $80 \mathrm{mg} / \mathrm{mL}$ ). After the assay, the cell fusion degree was counted, and the cell proliferation rate was calculated.

\subsection{Cell migration}

The cell migration of MKN-45 cells and MKN-74 cells after ACBP-S-Se treatments was determined by the IncuCyte live cell workstation according to our previous studies. Briefly, MKN-45 and MKN-74 cells were inoculated into a 96 -well plate at a density of $5 \times 10^{4} /$ well. After scratching, the cells were treated with ACBP-S-Se. Here, for MKN-45 and MKN-74 cell the control group was not treated with any additional 
ACBP-S-Se $(0 \mathrm{mg} / \mathrm{mL})$, while the experimental group was treated with different concentrations of ACBP-SSe $(1 \mathrm{mg} / \mathrm{mL}$ and $5 \mathrm{mg} / \mathrm{mL})$. The 96 -well plate with drug treatment after the scratch was placed in the IncuCyte live cell workstation, and cell proliferation was recorded for $36 \mathrm{~h}$ at intervals of $2 \mathrm{~h}$. After the assay, the original data were analyzed according to the scratch wound healing protocol.

\subsection{Functional enrichment of oxidative stress-related genes}

The screening and enrichment analysis of oxidative stress-related genes, network diagram of functional enrichment and association of genes with oxidative stress were evaluated by biological information analysis.

\subsection{Reverse transcription PCR and Real-time PCR Analyses}

After drug treatments for $24 \mathrm{~h}$, the total RNA was extracted with TRIzol reagent (79306, Gibco, Shanghai, China), and then cDNA was synthesized according to the manufacturer's instructions (Prime ScriptTM RT reagent kit with gDNA Eraser, RR047A, Takara, Dalian, China). For PCR amplification, specific primers were designed on the NCBI website and commercially synthesized by Invitrogen (Shanghai, China). Realtime PCR was performed within a Thermo Pikoreal machine with commercial kits (RR820A, Premix Taq ${ }^{\text {TM }}$, Takara, Dalian, China).

The PCRs started with an initial melting cycle for $5 \mathrm{~min}$ at $95^{\circ} \mathrm{C}$, followed by 35 cycles of melting at $95^{\circ} \mathrm{C}$ for $30 \mathrm{~s}$, annealing at $58^{\circ} \mathrm{C}$ for $30 \mathrm{~s}$ and expansion at $72^{\circ} \mathrm{C}$ for $30 \mathrm{~s}$. The ubiquitously expressed $\beta$-actin gene was used as an internal control. The qualities of the PCRs were confirmed by melting curve analyses, and all experiments were performed in triplicate. The relative mRNA expression was calculated using the $2^{-\Delta \Delta C t}$ method ${ }^{33}$. The primers for reverse transcription PCR and real-time PCR analyses are shown in Table 1.

Table 1

Primers for reverse transcription PCR and real-time PCR analyses.

\begin{tabular}{|ll|}
\hline Primer & Primer sequences \\
\hline hCDKN1A-F & GGGTGCGGTGATGGATAAA \\
\hline hCDKN1A-R & ACTGCTGAGAACAGGAAGAAC \\
hCCNB1-F & GATGCAGAAGATGGAGCTGAT \\
\hline hCCNB1-R & TCCCGACCCGTGGTTTT \\
hTXN-F & GAAGCTCTGTTTGGTGCTTTG \\
hTXN-R & CTCGTCTGCTTCCCTCTT \\
hMAP3K5-F & CCCAGAGAGAGACAGCAGATA \\
\hline hMAP3K5-R & CTCACTGAAAGAGCCCAGATAC \\
\hline
\end{tabular}




\section{Results}

\subsection{Determination of the chemical structure of ACBP-S-Se by UV and FT-IR spectroscopy}

As shown in Fig. 1A, the UV absorption value of ACBP was $203 \mathrm{~nm}$. The ultraviolet absorption of selenium chelated by ACBP was obvious at $206 \mathrm{~nm}$ and $210 \mathrm{~nm}$. It is predicted that there are new forms of $-\mathrm{NH}$ and $-\mathrm{OH}$. There was weak absorption at $220 \mathrm{~nm}$, and the formation of $-\mathrm{CNO}$ and $-\mathrm{C}-\mathrm{S}$ bonds may have occurred. The absorption intensity of the carbonyl groups was increased because - $\mathrm{NH}$ and $-\mathrm{OH}$ are cosolor groups. Therefore, as shown in figure $A$ to $B$, the $\lambda_{\max }$ of $U V$ absorption increased from 0.12 to $0.62 \mathrm{~mm}$. Compared with the maximum absorption peak of pure ACBP $\left(\lambda_{\max }=206 \mathrm{~nm}\right)$, the maximum absorption peak of ACBP-S-Se $\left(\lambda_{\max }=210-220 \mathrm{~nm}\right)$ moved to the long wave direction $(4 \sim 14 \mathrm{~nm})$. The height of the maximum absorption peak obviously increased. In the range of $210-220 \mathrm{~nm}$, there were two high absorption peaks, which represent the characteristic absorption peaks of $-\mathrm{C}=\mathrm{O}$ and $-\mathrm{NH},-\mathrm{OH}$ in RCONHR'. There may also be secondary amide functional groups in the product after the sulfhydrylation and deacetylation of ACBP. From the FT-IR analysis of Fig. 1C, the distinction between the two maps (ACBP and ACBP-S-Se) was very obvious, indicating that the ACBP-S-Se curve represents the formation of a new substance, which is different from ACBP. In the ACBP-S-Se curve, $535 \mathrm{~cm}^{-1}$ and $640 \mathrm{~cm}^{-1}$ are the vibrational peaks of the Se-Se bond, and $736.8 \mathrm{~cm}^{-1}, 721 \mathrm{~cm}^{-1}$ and $775 \mathrm{~cm}^{-1}$ belong to the absorption peak of the C-Se bond. Moreover, $2336 \mathrm{~cm}^{-1}$ is the unique absorption peak of selenium, while $2600 \mathrm{~cm}^{-1}$ is the characteristic absorption peak of $-\mathrm{SH}$, and $3391 \mathrm{~cm}^{-1}, 1585.5 \mathrm{~cm}^{-1}$ and $1406.2 \mathrm{~cm}^{-1}$ are the characteristic absorption peaks of secondary amide, these peaks are different from those in the ACBP curve as the absorption strength is enhanced. The above results indicate that ACBP binds with selenium to form ACBP-S-Se, and the ACBP chain is linked with sulfhydryl groups by amide bonds to form the ACBP chelate selenium complex.

\subsection{Determination of the chemical structure of ACBP-S-Se by 13C NMR and H NMR}

In the H NMR spectra, the absorption peaks of $-\mathrm{OH},-\mathrm{NH}$ and $-\mathrm{SH}$ can be found in the attachment of $\delta 2.31$, $\delta 6 \sim 8.2$ and $\delta 1.43$, respectively (Fig. 1D). At the same time, there are different absorption peaks and different chemical shifts. In the $13 \mathrm{C}$ NMR spectra, in the attachment of $\delta 180$, there are absorption peaks of $\mathrm{CHO}$ and -C-S at $\delta 100$ and absorption peaks of different degrees and different chemical shifts at the same time. The results showed that there were different amounts of binding between bioactive polypeptides and selenium in different proportions, so the molecular structure of ACBP-S-Se was inferred.

\subsection{Determination of the chemical structure of ACBP-S-Se by XPS}

As observed in Figure. 2, both types of polymers composed of pure ACBP and ACBP-S-Se exhibited significant differences in all four peaks in the XPS spectra: C $1 \mathrm{~s}(284.0-285.0 \mathrm{eV}), \mathrm{N} 1 \mathrm{~s}(399.0-400.0 \mathrm{eV})$, S 2p (166.8-167.57 eV) and Se 3d (55-60 eV) (Table 2). As seen from the XPS spectra of nitrogen, the binding energy decreased from $399.65 \mathrm{eV}$ in ACBP to $399.02 \mathrm{eV}$ in ACBP-S-Se. However, as seen from the XPS spectra of sulfur, the binding energy increased from $166.8 \mathrm{eV}$ in ACBP to $167.57 \mathrm{eV}$ in ACBP-S-Se. 
Additionally, the binding energy of Se formed at $56.2 \mathrm{eV}$ in ACBP-S-Se, the new -SH = Se bond in ACBP-SSe was formed, the electronegativity of Se 3d increased, and the binding energy also increased.

Table 2

Assignments of the main special bands in ACBP-S-Se based on binding energy.

\begin{tabular}{|llll|}
\hline Element & ACBP/eV & ACBP-S-Se/eV & Assignments \\
\hline $\mathrm{C} 1 \mathrm{~s}$ & 284.7 & 284.87 & $\mathrm{C}-\mathrm{C}$ \\
$\mathrm{N} 1 \mathrm{~s}$ & 399.65 & 399.02 & $\mathrm{NH}_{2}, \mathrm{NH}_{3}{ }^{+}$ \\
\hline $\mathrm{S} 2 \mathrm{p}$ & 166.8 & 167.57 & $\mathrm{NO}_{2} \mathrm{SO}_{3}, \mathrm{~K}_{2} \mathrm{SO}_{3}, \mathrm{pNH}_{2} \mathrm{C}_{6} \mathrm{H}_{4} \mathrm{SO}_{2} \mathrm{C}_{6} \mathrm{H}_{4} \mathrm{NH}_{2}{ }^{+}$ \\
$\mathrm{Se} 3 \mathrm{~d}$ & -- & 56.2 & $-\mathrm{SH}=\mathrm{Se}$ \\
\hline
\end{tabular}

\subsection{SEM-EDX observation and ICP-MS of ACBP-S-Se}

As shown in Fig. 3A, the morphology of ACBP is a coarse fibrous structure. From the morphology of the ACBP-S-Se in Fig. $3 C$, the particle structure has an average uneven grain of $5 \mu \mathrm{m}$ in diameter. Compared with ACBP, in ACBP-S-Se, the distribution of the elements $\mathrm{C}, \mathrm{N}$ and $\mathrm{O}$ decreased, while the distribution of elements Se and S increased.

As indicated in Fig. 3D, the selenium content was up to $0.28 \%$. The selenium content was 829.030 $[\mathrm{He}] / \mathrm{PPb}$ when the ratio of ACBP and selenium was 2:1 (Table 3). The content of selenium in the ACBP molecule was 2.1 per mole.

Table 3

Concentration of selenium in ACBP chelate selenium as determined by ICP-MS.

\begin{tabular}{|llllc|}
\hline Sample & $\begin{array}{l}\text { Concentration of selenium } \\
(\mathrm{Se}[\mathrm{He}] / \mathrm{PPb})\end{array}$ & $\begin{array}{l}\text { Concentration of } \\
\text { ACBP } \\
(\mathrm{mg} / \mathrm{mL})\end{array}$ & RSD & $\mathrm{nSe} / \mathrm{nACBP}$ \\
\hline $\begin{array}{l}\text { ACBP:Se } \\
(2: 1)\end{array}$ & 829.030 & 0.05 & 0.3 & 2.1 \\
\hline
\end{tabular}

\subsection{The inhibitory effect of ACBP-S-Se on tumor cell lines}

As shown in Fig. 4 ( $A$ and $B$ ), the growth of MKN-45 and MKN-74 cells was inhibited after treatment with ACBP-S-Se, and the rates of apoptotic cells were increased in a dose-dependent manner. The inhibition of MKN-45 and MKN-74 cell proliferation was not obvious with increasing concentrations of ACBP-S-Se from $5 \mathrm{mg} / \mathrm{mL}$ to $80 \mathrm{mg} / \mathrm{mL}$. 
The wound healing ability of MKN-45 and MKN-74 cells was detected in the control group and after treatment with different concentrations of ACBP-S-Se and was increased with increasing ACBP-S-Se concentrations, especially after treatment with $1 \mathrm{mg} / \mathrm{mL}$ ACBP-S-Se (Figure $C$ and D). The results indicated that from $1 \mathrm{mg} / \mathrm{mL}$ to $5 \mathrm{mg} / \mathrm{mL}$ ACBP-S-Se has the ability to inhibit cell migration.

\subsection{Functional Gene Selection Principles}

The results of functional gene analyses showed 911 upregulated genes and 1122 downregulated genes after ACBP-S-Se treatment in MKN-45 cells. The screening results and enrichment analysis of oxidative stress-related genes are shown in Table 4.

Table 4

Screening and enrichment analysis of oxidative stress-related genes.

\section{Classification Characterization}

G0:0006979 response to oxidative stress

G0:0008631 intrinsic apoptotic signaling pathway in response to oxidative stress

GO:0034599 cellular response to oxidative stress

G0:0036475 neuron death in response to oxidative stress

G0:0043619 regulation of transcription from RNA polymerase II promoter in response to oxidative stress

GO:0097193 intrinsic apoptotic signaling pathway

GO:1900407 regulation of cellular response to oxidative stress

GO:1900408 negative regulation of cellular response to oxidative stress

GO:1902175 regulation of oxidative stress-induced intrinsic apoptotic signaling pathway

GO:1902176 negative regulation of oxidative stress-induced intrinsic apoptotic signaling pathway

GO:1902882 regulation of response to oxidative stress

GO:1902883 negative regulation of response to oxidative stress

G0:1903202 negative regulation of oxidative stress-induced cell death

G0:1903204 negative regulation of oxidative stress-induced neuron death

GO:1903376 regulation of oxidative stress-induced neuron intrinsic apoptotic signaling pathway

GO:1903377 negative regulation of oxidative stress-induced neuron intrinsic apoptotic signaling pathway

hsa04068 FoxO signaling pathway

hsa04115 p53 signaling pathway 
From the functional enrichment results of oxidative stress-related genes, a total of 75 genes with significant differences were selected (Fig. 5A). From the gene interaction mapping, CDKN1A, CCNB1, TXN and MAP $3 K 5$ were extracted due to the role of most genes associated with them and the significantly enriched pathways, which can be used as downstream molecules (Fig. 5B).

In Fig. 6A, according to the interaction of genes related to oxidative stress and IncRNA, networks of oxidative stress genes and IncRNA interactions (IncRNA FPKM > 5) were constructed via IncRNA trans and cis analysis (TRANS_ENERGY<-50). The results showed that the network contained 55 genes related to oxidative stress and 37 IncRNAs.

The selected IncRNAs included MSTRG.13268.2, ENST00000508832, ENST00000580180, ENST00000454068, ENST00000607476, ENST00000504539, ENST00000326677, ENST00000448718, ENST00000531126 and MSTRG.5031.1. As shown in Fig. 6B-E and Table 5, the expression of oxidative stress-related genes (the 4 selected genes) in TCGA and the expression of CDKN1A increased after treatment with ACBP-S-Se, but the expression of this gene was lower in tumor samples than in paracancerous samples. The expression of the other three genes decreased after treatment with ACBP-SSe but was lower in tumor samples than in paracancerous samples.

Table 5

Expression of CDKN1A, CCNB1, MAP3K5 and TXN under oxidative stress in TCGA.

\begin{tabular}{|llllll|}
\hline Gene name & MKN-45-ACBP & MKN-45 & fc & log2(fc) & Regulation \\
\hline CDKN1A & 264.77 & 9.55 & 25.92 & 4.7 & up \\
\hline CCNB1 & 8.99 & 25.89 & 0.33 & -1.62 & down \\
\hline MAP3K5 & 0.99 & 2.94 & 0.32 & -1.66 & down \\
\hline TXN & 38.74 & 74.24 & 0.49 & -1.03 & down \\
\hline
\end{tabular}

\subsection{Relative gene expression levels}

As shown in Fig. 6, the CDKN1A, CCNB1, TXN and MAP3K5 gene expression levels in GSE-1, MKN-45 and MKN-74 cells were analyzed by real-time PCR. In the GSE-1, MKN-45 and MKN-74 cells, the gene expression levels of $C D K N 1 A$ and $T X N$ were significantly increased after ACBP-S-Se treatment compared with the control condition. In addition, the gene expression level of CCNB1 and MAP3K5 in GSE-1 cells was significantly different between the control group and ACBP-S-Se treatment group; however, the gene expression level of MAP3K5 in MKN-45 cells was significantly increased, and the gene expression level of MAP3K5 in MKN-74 cells was significantly decreased after ACBP-S-Se treatment. The results indicated that $C D K N 1 A$ and $T X N$ have the ability to protect cells to reduce oxidative stress and promote cell growth arrest. 


\section{Discussion}

Gastric cancer (GC) is one of the major threats to human health worldwide. Previous studies have demonstrated that ACBP combined with oxaliplatin (OXA) significantly inhibited the growth of MKN-45 cells. Recently, the replacement of peptides with chemical modifications to achieve the same therapeutic effects as natural peptide counterpart in combined chemotherapeutics has been rapidly developed. Furthermore, the incorporation of the Se atom in amino acids and peptides is mostly restricted to selenocysteine derivatives, and there is still a need for further developments toward the synthesis of amino acid-derived chiral selenium compounds, including potential candidates for biological evaluations. Here, ACBP was modified by sulfhydrylation to combined Se to form the ACBP selenium chelate, and its properties and inhibitory effect on GC cells in vitro was investigated.

From the FT-IR, XPS, 13C NMR and H NMR, SEM, EDX and ICP-MS analyses, the results show that new functional groups were formed, such as -C-Se, Se-Se, $-\mathrm{SH}=\mathrm{Se}$ and - CONH. ICP-MS techniques are used to determine the single elements and multielement analysis in synthetic drugs. The higher content of Se in ACBP-S-Se than in ACBP indicates that Se may have been successfully incorporated into the molecular chain of ACBP. Meanwhile, Se is a trace element that is beneficial to humans depending on its concentration and chemical speciation ${ }^{34}$. Studies have shown that different Se compounds could reduce cancer growth as potential anticancer drugs ${ }^{35}$. Selenium deficiency led to increased cell apoptosis and decreased cell viability. Selenium supplementation may mitigate these alterations ${ }^{36}$. Interestingly, in this study, we showed that ACBP-S-Se at $5 \mathrm{mg} / \mathrm{mL}$ effectively inhibited the proliferation of MKN-45 and MKN74 cells. In addition, the wound healing of MKN-45 and MKN-74 cells after ACBP-S-Se treatment reduced cell migration.

The polypeptide has high glutathione peroxidase (GPX) activity and can clear the free radicals in human body ${ }^{37}$. Although several functions of selenoproteins are unknown, many disorders are related to alterations in selenoprotein expression or activity. Selenium insufficiency and polymorphisms or mutations in the genes encoding selenoproteins and synthesis cofactors are involved in the pathophysiology of many diseases, including immune dysfunctions and cancer ${ }^{24}$. Considering the perspective of oxidative stress to explore the ceRNA mechanism of ACBP-S-Se in the treatment of GC, it is necessary to determine the changes in the expression of oxidative stress-related genes after ACBP-S-Se treatment. By carefully studying oxidative stress-related pathways and genes, functional genes were detected.

From all these genes, the ones that were consistently regulated were the selenoprotein genes. Furthermore, the Se-specific effects noted were caused primarily by Se deficiency and not high Se ${ }^{38}$. A total of 75 genes with significant differences were selected. From the gene interaction mapping, CDKN1A, CCNB1, TXN and MAP3K5 were selected. The cyclin-dependent kinase inhibitor $1 \mathrm{~A}$ (CDKN1A, also known as p21), a cell-cycle-dependent kinase suppressor molecule, has been shown to protect cells from oxidative stress damages ${ }^{39}$. Cyclin B1 (CCNB1), also inhibits certain specific factors in ubiquitinproteasome ${ }^{40}$. For example, hydrogen peroxide prevents ubiquitin (Ub) from binding to late-promoting 
complex (APC/C) substrates, which also prevents the degradation of CCNB1 and thus promotes cell growth arrest caused by oxidative stress. Increased $C C N B 1$ expression has been observed in several cancers; for example, the expression of $C C N B 1$ in gastric cancer tissues was higher than that in normal gastric tissues ${ }^{41}$. However, ACBP-S-Se treatment decreased the expression of CCNB1 in MKN-45 and MKN-74 cells. The thioredoxin protein gene (TXN) plays an important role in cellular antioxidant defense ${ }^{42,43}$. Mitogen-activated protein kinase kinase kinase 5 (MAP3K5), also known as apoptotic signal-regulated kinase 1 , regulates the biological and physiological processes of apoptosis, immunity and gastric emptying by regulating the flow of apoptotic kinases ${ }^{44}$. Furthermore, MAP $3 K 5$, activated in response to stress signals, plays an important role in oxidative stress regulation, cell proliferation, differentiation and death, and immune response ${ }^{45}$. It has been shown that a molecular target of reactive oxygen species (ROS), thioredoxin (TXN/Trx), is an inhibitor of MAP $3 K 5^{46}$. Moreover, oxidation via ROS disrupts the binding of $\operatorname{Tr} x$ to $M A P 3 K 5$, resulting in apoptosis ${ }^{47}$. The results show that the formation of ACBP-S-Se negatively regulates MAP $3 K 5$ activity, thus attenuating the proapoptotic signal in MKN-74 cells. Inhibition of apoptosis via this mechanism would result in increased proliferation and survival, increasing the probability of tumorigenesis and/or metastases. Therefore, oxidative stress is closely related to the occurrence and development of cancer. Oxidative stress results in cell apoptosis/death, stressors alter the miRNA expression profile, and miRNAs play a role in the cell response to stress.

\section{Conclusion}

In summary, the application of sulfhydrylation and deacetylation is an effective method to enhance the chelating efficiency of ACBP and Se. According to the UV, FT-IR and 13C NMR, H NMR, XPS, EDX, and ICPMS analyses, Se was chelated into ACBP via sulfhydrylation; the sulfhydryl group was used as the binding site of Se and increased the chelating rate. Finally, the results presented herein suggest ACBP-SSe effectively inhibited the MKN-45 and MKN-74 cell growth and migration in vitro, which in turns suggests that ACBP-S-Se could be applied in the clinic.

\section{Declarations}

\section{Ethics approval and consent to participate}

Not applicable

\section{Consent for publication}

Not applicable

\section{Availability of data and materials}

Not applicable

\section{Competing interests}


The authors declare that they have no competing interests

\section{Funding}

This study was supported financially by the National Natural Science Foundation of China (81860416, 81660468), and General Project and Doctor starts of affiliated Hospital of Inner Mongolia Medical University (NYFY YB044, NYFY BS 2018), Inner Mongolia Autonomous Region University "Youth Science and Technology Talent Support Program" (NJYT-20-B17), and Scientific and Technological Innovation of College Students in Inner Mongolia Medical University 2020 Project Task of "Cultivation of Excellence" Project (YCPY20200033) and Laboratory Open Projects (2020ZN47) .

\section{Authors' contributions}

$\mathrm{XL}, \mathrm{XJW}, \mathrm{GL}, \mathrm{YNX}$ and $\mathrm{XLS}$ analyzed and interpreted the patient data. RY, FJ, CLS and XLW do the experiment. $X L$ was a major contributor in writing the manuscript. All authors read and approved the final manuscript.

\section{Acknowledgements}

Not applicable

\section{References}

1. Moloney, Jennifer, N., Cotter, Thomas and G. ROS signalling in the biology of cancer. Seminars in cell and developmental biology 2018.

2. Huang $T$, Wang-Johanning $F$, Zhou F, Kallon $\mathrm{H}$ and Wei Y. MicroRNAs serve as a bridge between oxidative stress and gastric cancer (Review). International Journal of Oncology 2016.

3. Zhang P, Shi L, Zhang T, Hong $L$ and Zou P. Piperlongumine potentiates the antitumor efficacy of oxaliplatin through ROS induction in gastric cancer cells. Cellular Oncology 2019.

4. Yu Y, Cui Y, Niedernhofer LJ and Wang Y. Occurrence, Biological Consequences, and Human Health Relevance of Oxidative Stress-Induced DNA Damage. Chemical Research in Toxicology 2016.

5. Sarkar FH, Kong D, Banerjee S, et al. Targeting CSCs in Tumor Microenvironment: The Potential Role of ROS-Associated miRNAs in Tumor Aggressiveness. Current Stem Cell Research \& Therapy 2014; 9:

6. Denicola GM. K-Ras oncogene-induced ROS detoxification promotes tumorigenesis. Dissertations \& Theses - Gradworks 2010.

7. Panhwar A, Tuzen M and Kazi T. Ultrasonic assisted dispersive liquid-liquid microextraction method based on deep eutectic solvent for speciation, preconcentration and determination of selenium species (IV) and (VI) in water and food samples. Talanta 2017; 175: 352-358.

8. Rayman MP. Rayman MP: The importance of selenium to human health. Lancet 356, 233-241. Lancet 2000; 356: 233-241. 
9. Gheorghiu ML and Badiu C. Selenium involvement in mitochondrial function in thyroid disorders. Hormones 2020.

10. Peng H, Zhang N, He M, Chen B and Hu B. Simultaneous speciation analysis of inorganic arsenic, chromium and selenium in environmental waters by 3-(2-aminoethylamino) propyltrimethoxysilane modified multi-wall carbon nanotubes packed microcolumn solid phase extraction and ICP-MS. Talanta 2015; 131: 266-272.

11. Colangelo L, He K, Whooley M, Daviglus M, Morris S and Liu K. Selenium exposure and depressive symptoms: the Coronary Artery Risk Development in Young Adults Trace Element Study. Neurotoxicology 2014; 41: 167-174.

12. Ni Z, Na F, Fang Z, Feng $Y$ and Ling K. Simultaneous multi-channel hydride generation atomic fluorescence spectrometry determination of arsenic, bismuth, tellurium and selenium in tea leaves. Food Chemistry 2011; 124: 1185-1188.

13. Achilli $C$, Ciana A and Minetti G. Brain, immune system and selenium: a starting point for a new diagnostic marker for Alzheimer's disease? Perspectives in Public Health 2018; 138 : 175791391877870.

14. Mckenzie RC, Arthur JR, Miller SM, et al. Selenium and the immune system. Nutrition \& Immune Function 2002.

15. Guo CH, Hsia S, Hsiung DY and Chen PC. Supplementation with Selenium yeast on the prooxidantantioxidant activities and anti-tumor effects in breast tumor xenograft-bearing mice. Journal of Nutritional Biochemistry 2015; 26.

16. Bingxin, Wanyan, Yunbo, et al. Selenium-Alleviated Hepatocyte Necrosis and DNA Damage in Cyclophosphamide-Treated Geese by Mitigating Oxidative Stress. Biological trace element research 2019.

17. Salonen JT. Selenium and human cancer. Annals of Clinical Research 18: 18-21.

18. Marco V, Sergio R, Margherita B and Gianfranco V. The Epidemiology of Selenium and Human Cancer. Advances in Cancer Research 2000; 86: 105-118.

19. Yin $\mathrm{CH}$, Jia HU, Yang MF, Liu SS and Song KY. Effect of selenium dioxide united DDP on the human ovarian cancer cells xenografts in nude mice and its mechanism. Shandong Medical Journal 2012.

20. Jia HU, Liu SS and Yun LI. EFFECT OF SELENIUM DIOXIDE ON CISPLATIN RESISTANCE IN OVARIAN CARCINOMA CELL LINE COC1/DDP. Modern Preventive Medicine 2010.

21. Arthur JR, Mckenzie RC and Beckett GJ. Selenium in the immune system. 11th International Symposium on Trace Elements in Man and Animals. 2003.

22. Arthur JR, Mckenzie RC and Beckett GJ. Selenium in the immune system. Journal of Nutrition 2003; 133: 1457 S.

23. Younis A, Rooks B, Khan S and Gould K. The effects of antifreeze peptide III (AFP) and insulin transferrin selenium (ITS) on cryopreservation of chimpanzee (Pan troglodytes) spermatozoa. Journal of andrology 1998; 19: 207-214. 
24. Evangelos Z, Isidoros S, Nikolaos K and Georgios D. Selenium-Dependent Antioxidant Enzymes: Actions and Properties of Selenoproteins. Antioxidants 2018; 7: 66.

25. Khoso PA, Yang Z, Liu C and Li S. Selenium Deficiency Downregulates Selenoproteins and Suppresses Immune Function in Chicken Thymus. Biological Trace Element Research 2015; 167: 4855.

26. Zakharia Y, Bhattacharya A and Rustum YM. Selenium targets resistance biomarkers enhancing efficacy while reducing toxicity of anti-cancer drugs: preclinical and clinical development. Oncotarget 2018; 9: 10765-10783.

27. Yi-Chao Yang NL, Yudi Deng, Yongxin Zeng, Jingyan Pei, Hangyang Bao, Li Liu. A whey protein peptide-selenium chelate with antioxidant activity and preparation method and application. 2018.

28. Zhang C, Jia S and Su X. Effect of anticancer bioactive peptide on the gene expression of human gastric cancer BGC-823 cells. 2010.

29. Li X, Wu H, Ouyang X, Zhang B and Su X. New bioactive peptide reduces the toxicity of chemotherapy drugs and increases drug sensitivity. Oncology Reports 2017.

30. Braga AL, Lüdtke DS, Paixão MW, Alberto EE, Stefani HA and Juliano L. Straightforward Synthesis of Non-Natural Selenium Containing Amino Acid Derivatives and Peptides. European Journal of Organic Chemistry 2005; 2005: 4260-4264.

31. Lv S, Taha A, Hu H, Lu Q and Pan S. Effects of Ultrasonic-Assisted Extraction on the Physicochemical Properties of Different Walnut Proteins. Molecules Online 2019; 24.

32. Xian, Li, Long, et al. Bioactive peptides sensitize cells to anticancer effects of oxaliplatin in human colorectal cancer xenografts in nude mice. Protein and peptide letters 2019.

33. Liu G, Li S, Yuan H, et al. Effect of sodium alginate on mouse ovary vitrification. Theriogenology 2018: 78.

34. Castro Grijalba A, Fiorentini EF and Wuilloud RG. Ionic liquid-assisted separation and determination of selenium species in food and beverage samples by liquid chromatography coupled to hydride generation atomic fluorescence spectrometry. Journal of Chromatography A 2017; 1491: 117-125.

35. Fu X, Yang Y, Li X, et al. RGD peptide-conjugated selenium nanoparticles: antiangiogenesis by suppressing VEGF-VEGFR2-ERK/AKT pathway. Nanomedicine Nanotechnology Biology \& Medicine 2016: 1627-1639.

36. Zoidis E, Seremelis I, Kontopoulos N and Danezis GP. Selenium-Dependent Antioxidant Enzymes: Actions and Properties of Selenoproteins. Antioxidants (Basel, Switzerland) 2018; 7.

37. Guimin L, Sun YE and Shaowu LU. Selenium-containing polypeptide and its use in medicine, food etc.

38. Sunde RA and Raines AM. Selenium Regulation of the Selenoprotein and Nonselenoprotein Transcriptomes in Rodents. Advances in Nutrition 2011; 2: 138-150.

39. Surhone LM, Tennoe MT, Henssonow SF, Macromolecule and Acid N. Cyclin-Dependent Kinase Inhibitor 1C. 2011. 
40. He J, Yu S, Guo C, Tan L and Peng C. Polyphyllin I induces autophagy and cell cycle arrest via inhibiting PDK1/Akt/mTOR signal and downregulating cyclin B1 in human gastric carcinoma HGC27 cells. Biomedicine \& Pharmacotherapy 2019; 117: 109189.

41. Sheng-Hui Y, Yan-Jing H and Chun Q. Study on the Effect of CCNB1 Expression on the Prognosis of Gastric Cancer Based on Databases. China Digital Medicine 2020.

42. Hanschmann EM and Berndt C. Thioredoxin (TXN). 2018.

43. Yang J, Hamid S, Cai J, Liu Q and Xu S. Selenium deficiency-induced thioredoxin suppression and thioredoxin knock down disbalanced insulin responsiveness in chicken cardiomyocytes through PI3K/Akt pathway inhibition. Cellular Signalling 2017; 38: 192.

44. Pu L, Zhang LC, Zhang JS, et al. Porcine MAP3K5 analysis: molecular cloning, characterization, tissue expression pattern, and copy number variations associated with residual feed intake. Genetics \& Molecular Research Gmr 2016; 15.

45. Brueggemeier U, Geerts A and Golz S. Diagnostics and therapeutics for diseases associated with mitogen-activated protein kinase kinase kinase 5 (map3k5). WO, 2005.

46. Tzeng HE, Tsai $\mathrm{CH}$, Chang ZL, et al. Interleukin-6 induces vascular endothelial growth factor expression and promotes angiogenesis through apoptosis signal-regulating kinase 1 in human osteosarcoma. Biochemical Pharmacology 2013; 85: 531-540.

47. Prickett TD, Zerlanko B, Gartner JJ, Parker SCJ and Samuels Y. Somatic Mutations in MAP3K5 Attenuate Its Proapoptotic Function in Melanoma through Increased Binding to Thioredoxin. Journal of Investigative Dermatology 2015; 134: 452.

\section{Figures}


A

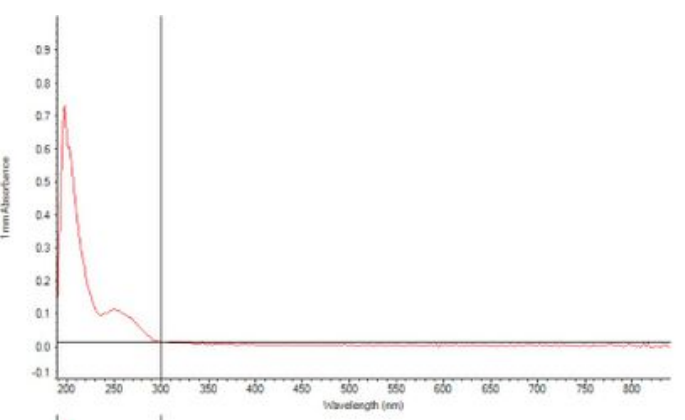

B

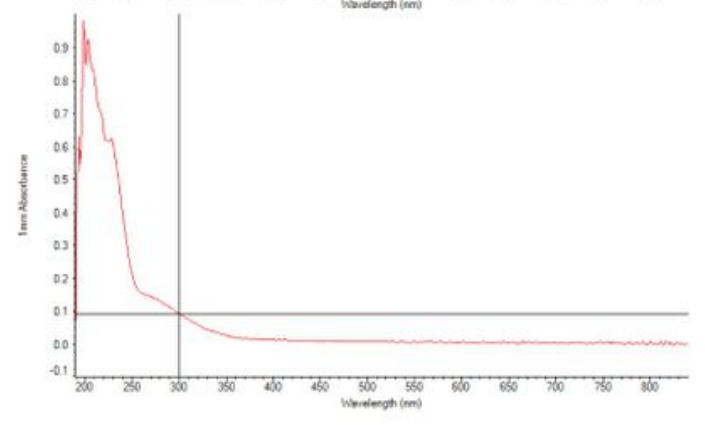

D

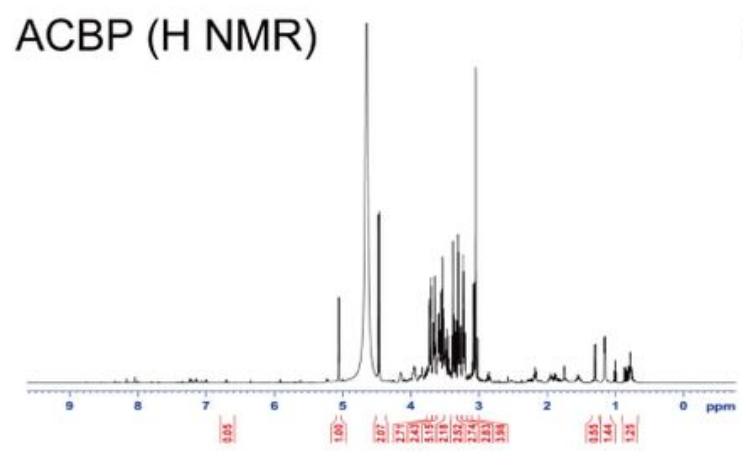

C

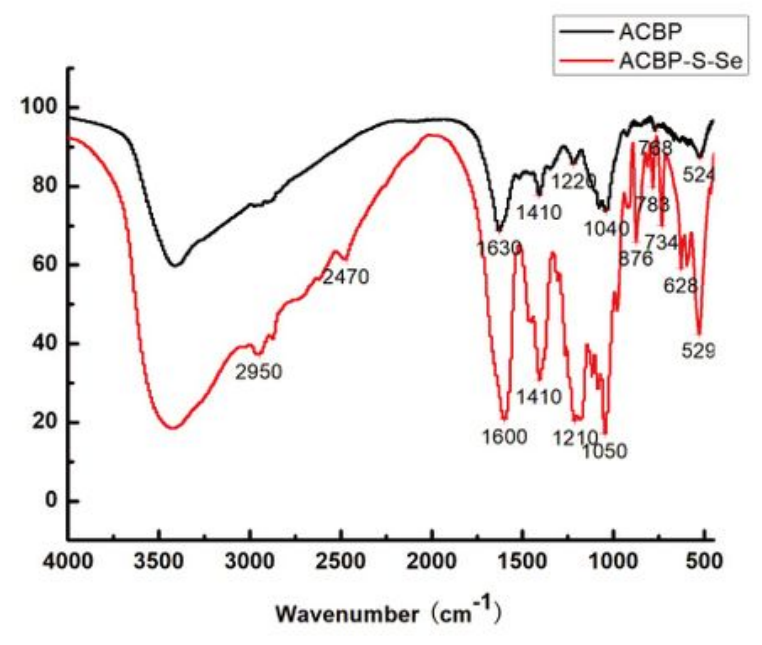

ACBP (13C NMR)

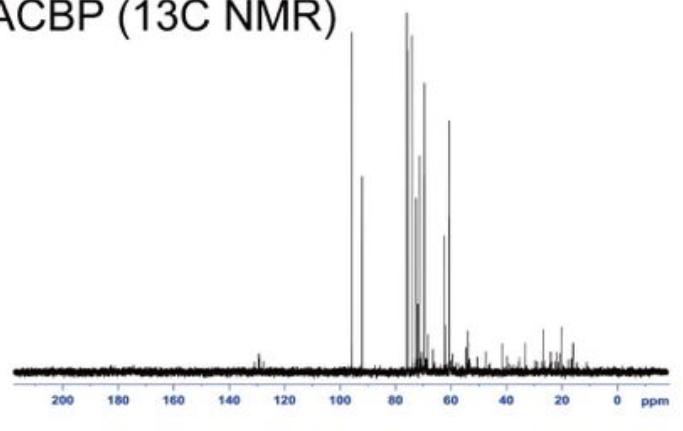

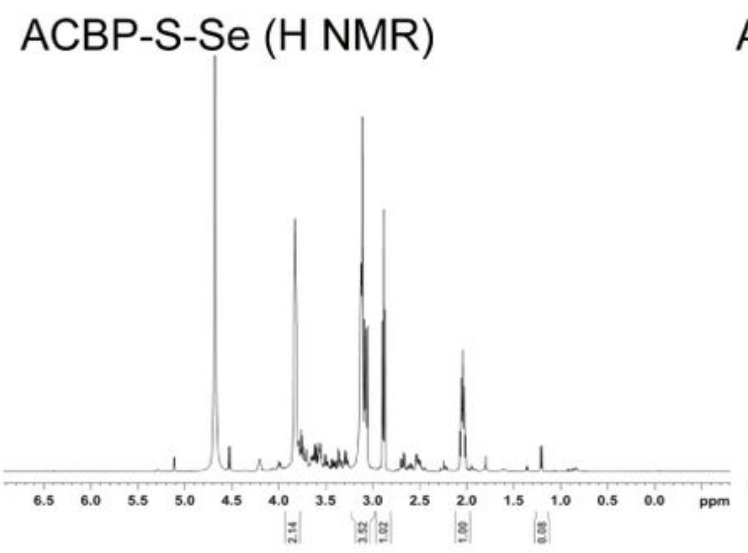

ACBP-S-Se (13C NMR)

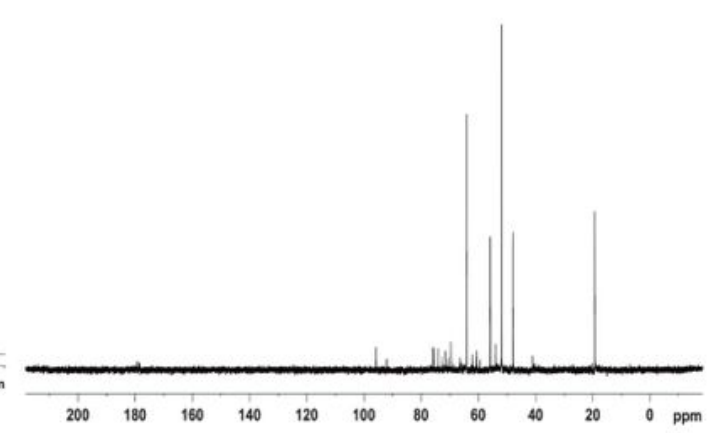

\section{Figure 1}

UV spectroscopy results of ACBP (A) and ACBP-S-Se (B); FT-IR results of ACBP and ACBP-S-Se; (C, D), $13 C$ NMR and $H$ NMR results of ACBP and ACBP-S-Se. 

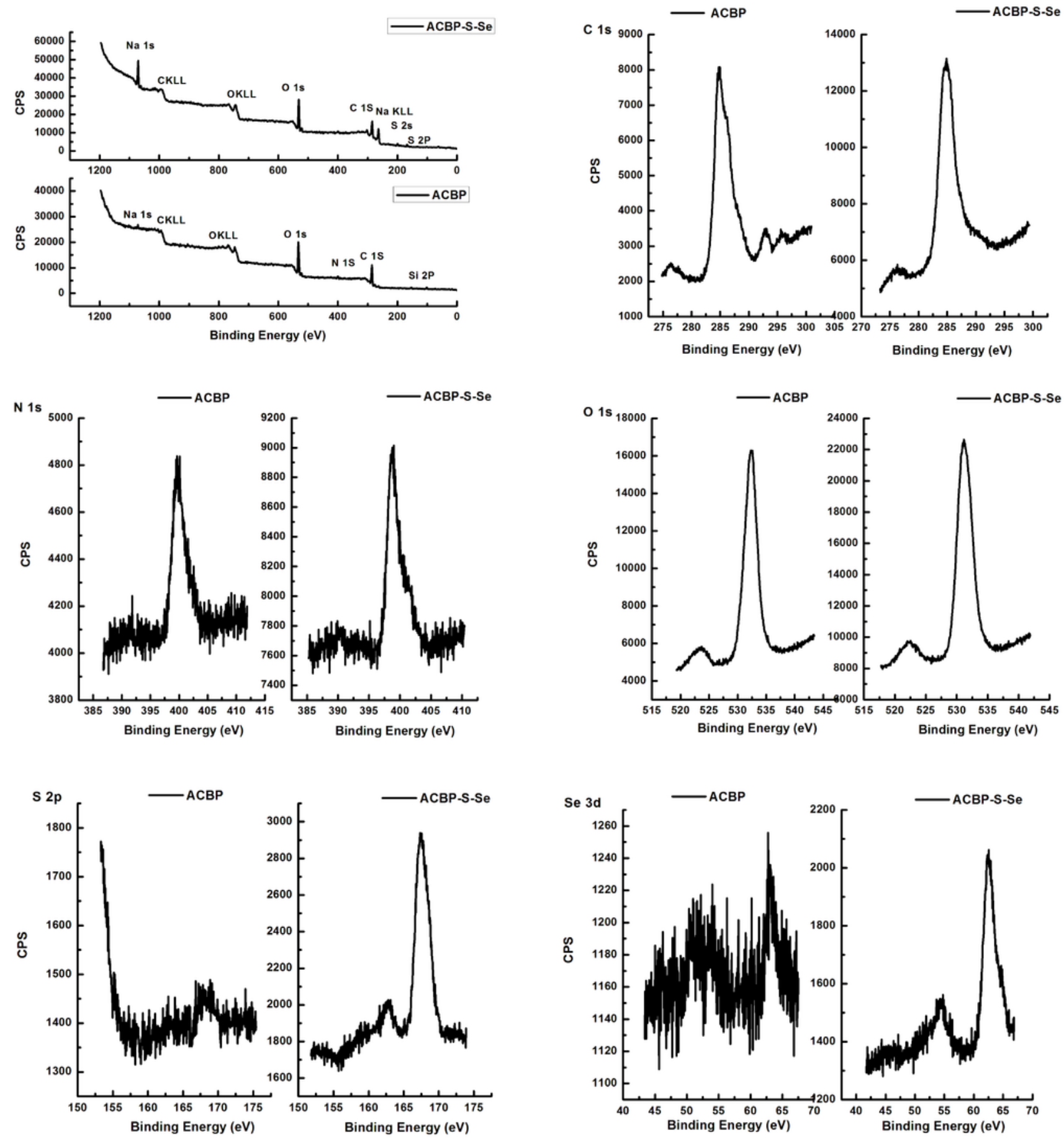

\section{Figure 2}

The XPS results of ACBP-S-Se, including the C, N, O, S, and Se elements. 
A
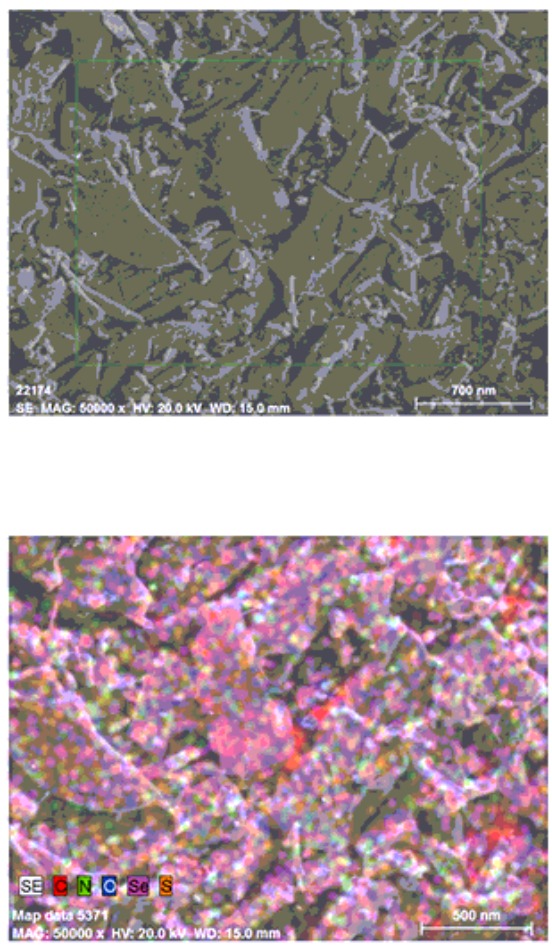

\section{C}
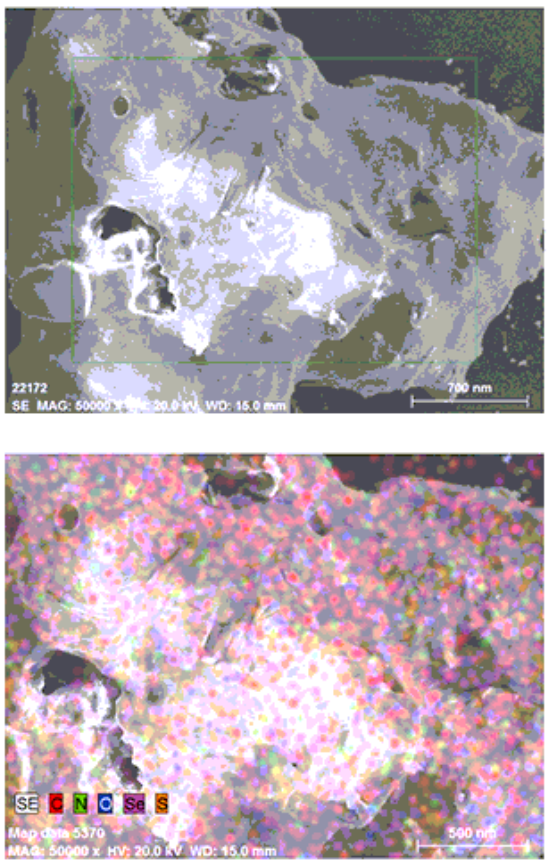
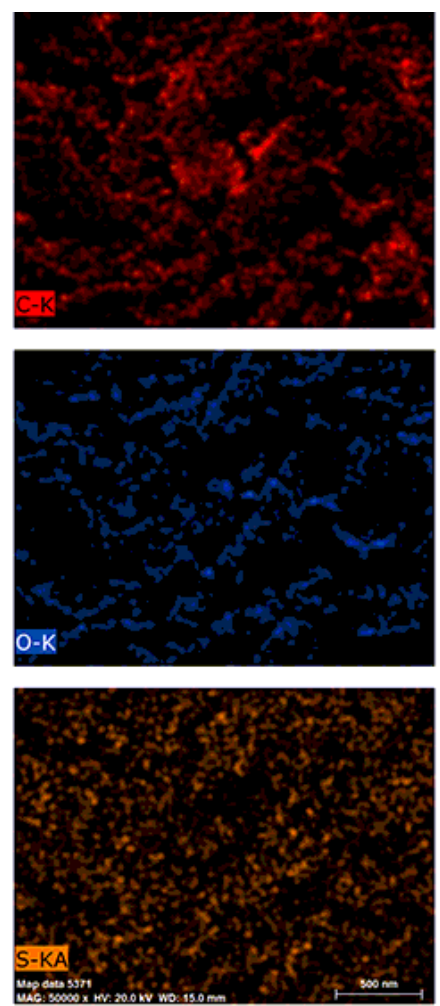

Se-KA
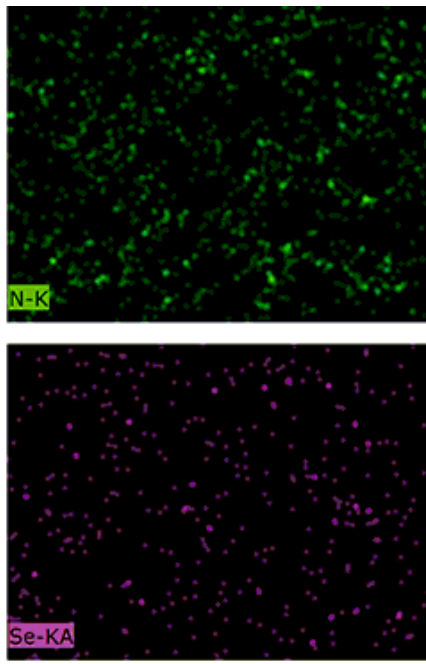

B
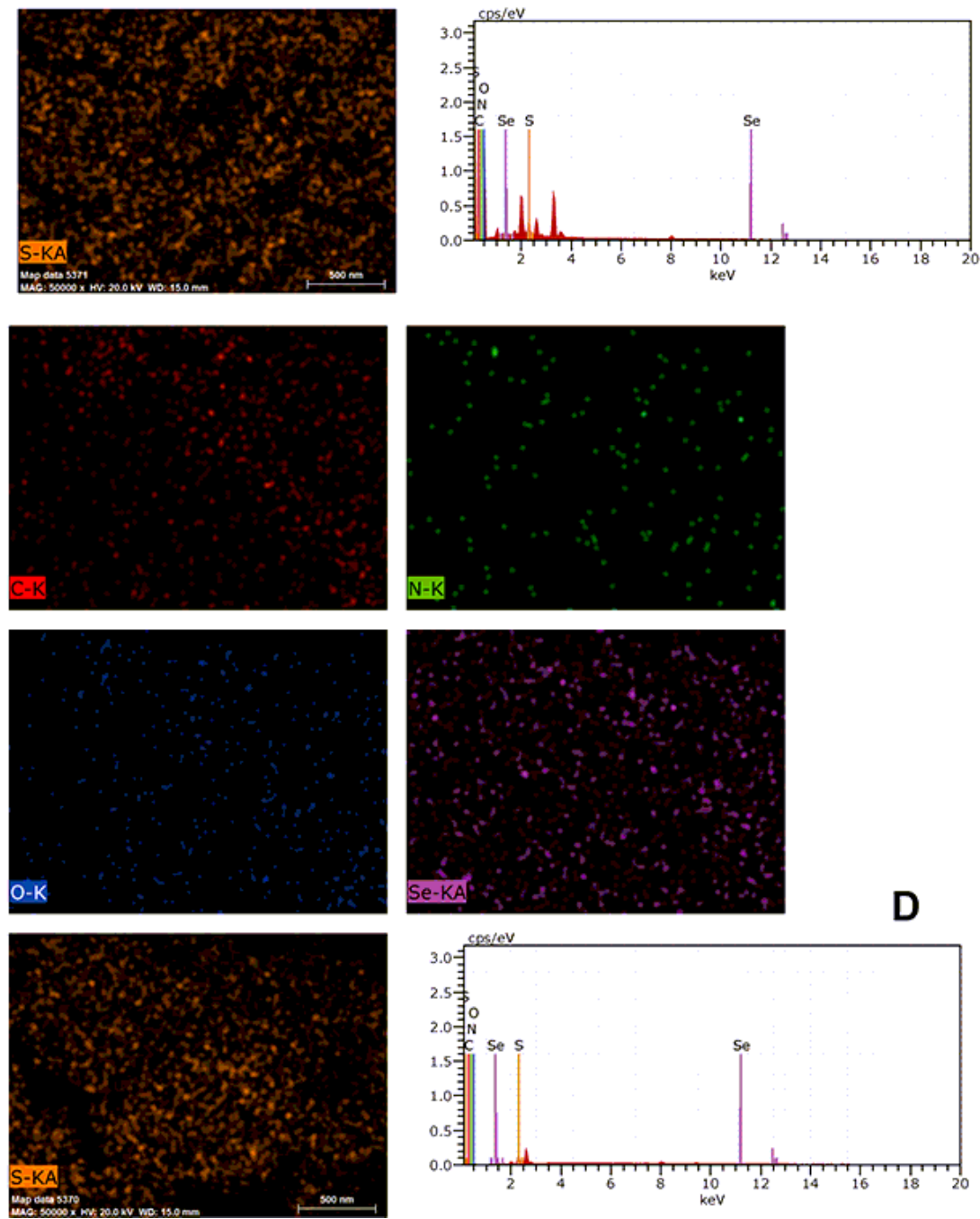

\section{Figure 3}

The SEM and EDX results (distribution of the elements $C, N, O, S e, S$ ) of ACBP (A) and ACBP-S-Se (B) after vacuum freeze drying; the elemental content of ACBP (C) and ACBP-S-Se (D). 
A

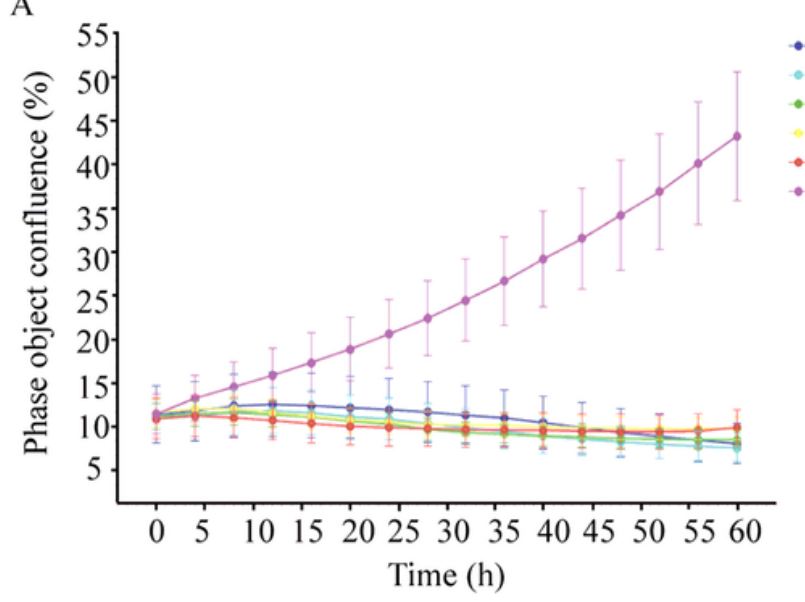

$\mathrm{C}$

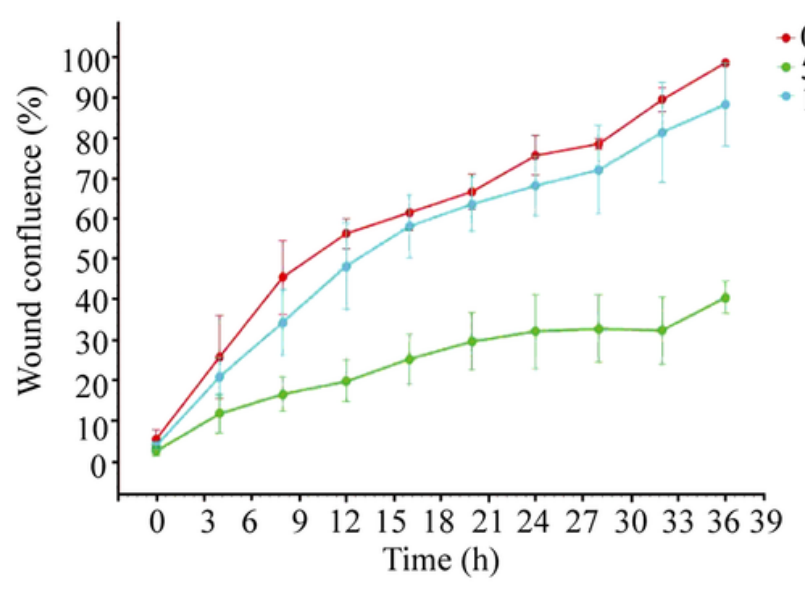

B
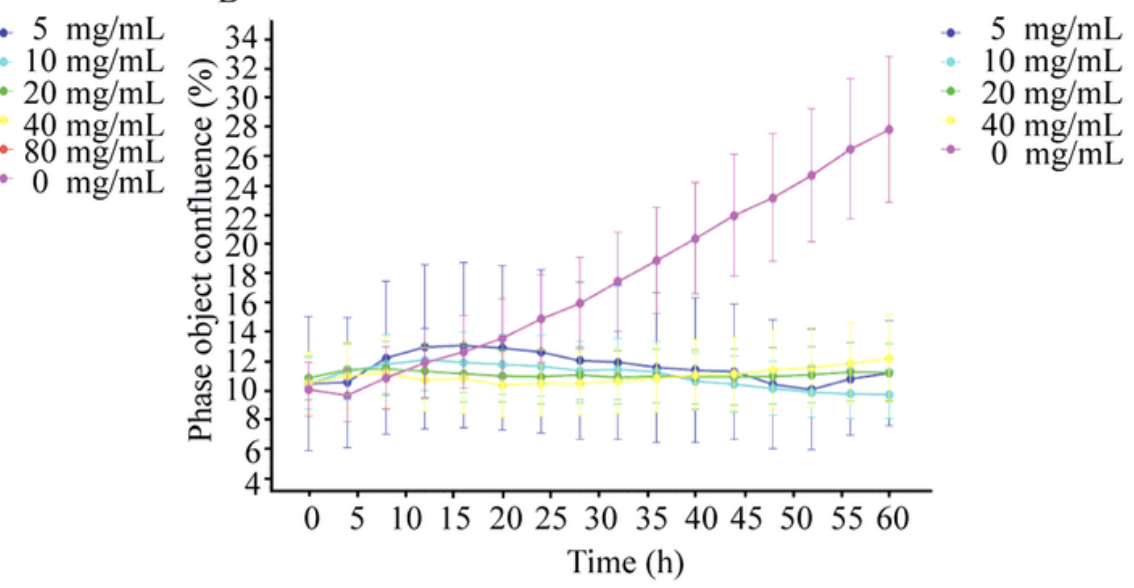

D

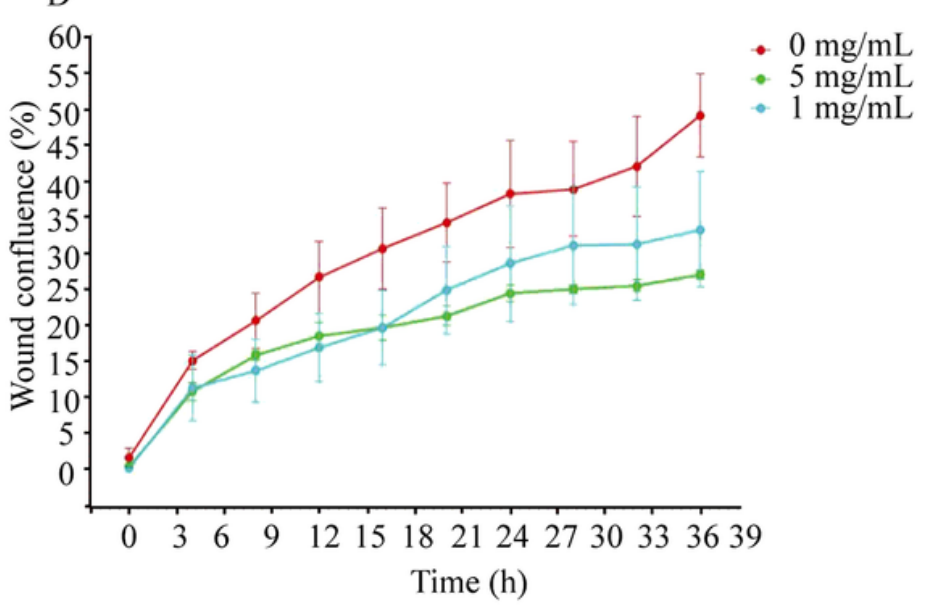

\section{Figure 4}

The proliferation of MKN-45 (A) and MKN-74 cells (B) after treatment with different concentrations of ACBP-S-Se was detected by the IncuCyte live cell workstation. Wound healing of MKN-45 (C) and MKN-74 cells (D) treated with different concentrations of ACBP-S-Se as detected by the IncuCyte live cell workstation after the cell wound scratch assay. ACBP-S-Se $(0 \mathrm{mg} / \mathrm{mL})$ was used as the control group. 
A

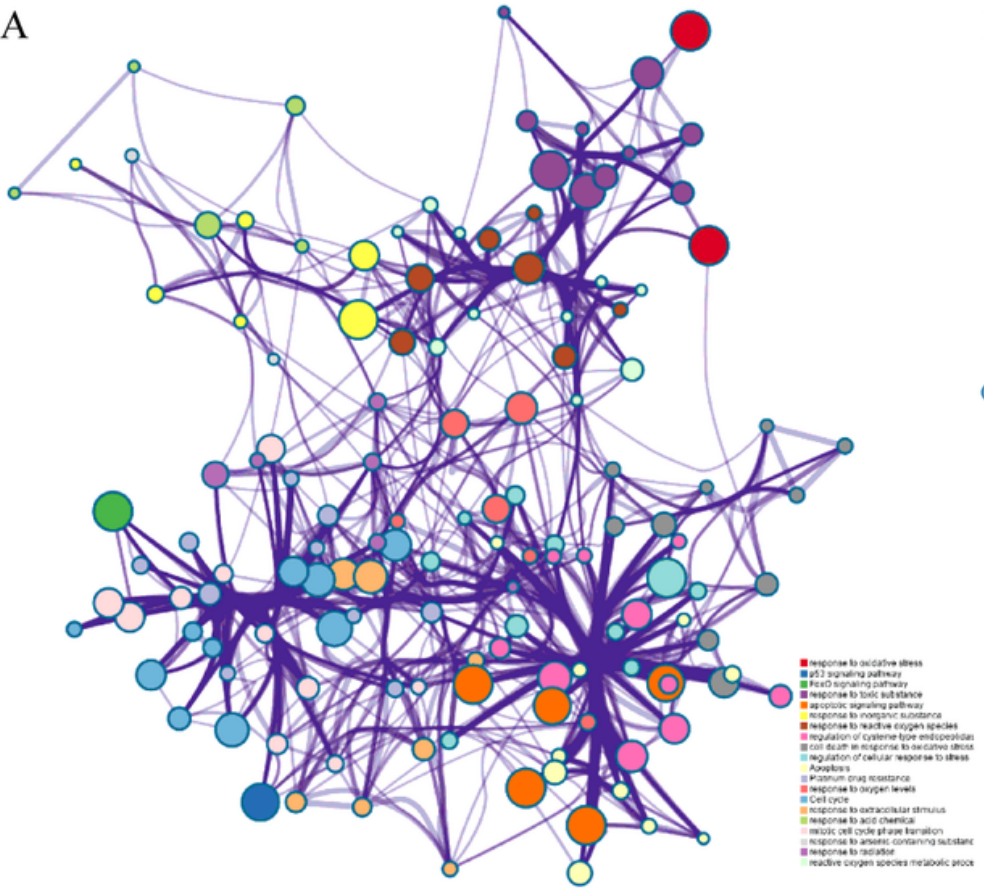

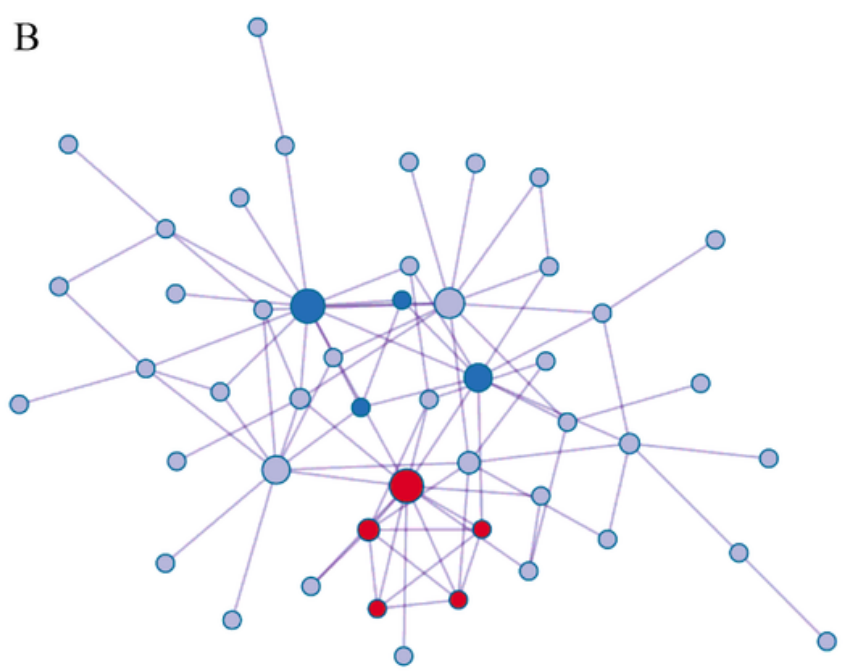

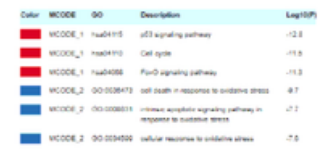

Figure 5

A, Functional enrichment and association network diagrams of oxidative stress-related genes (different colors represent different functions. The larger the dots are, the more genes are enriched. The thicker the lines are, the more genes have the same function) B, Interaction of oxidative stress-related genes (Each point represents a gene, and the larger the circle is, the more genes that are associated with it). 
A

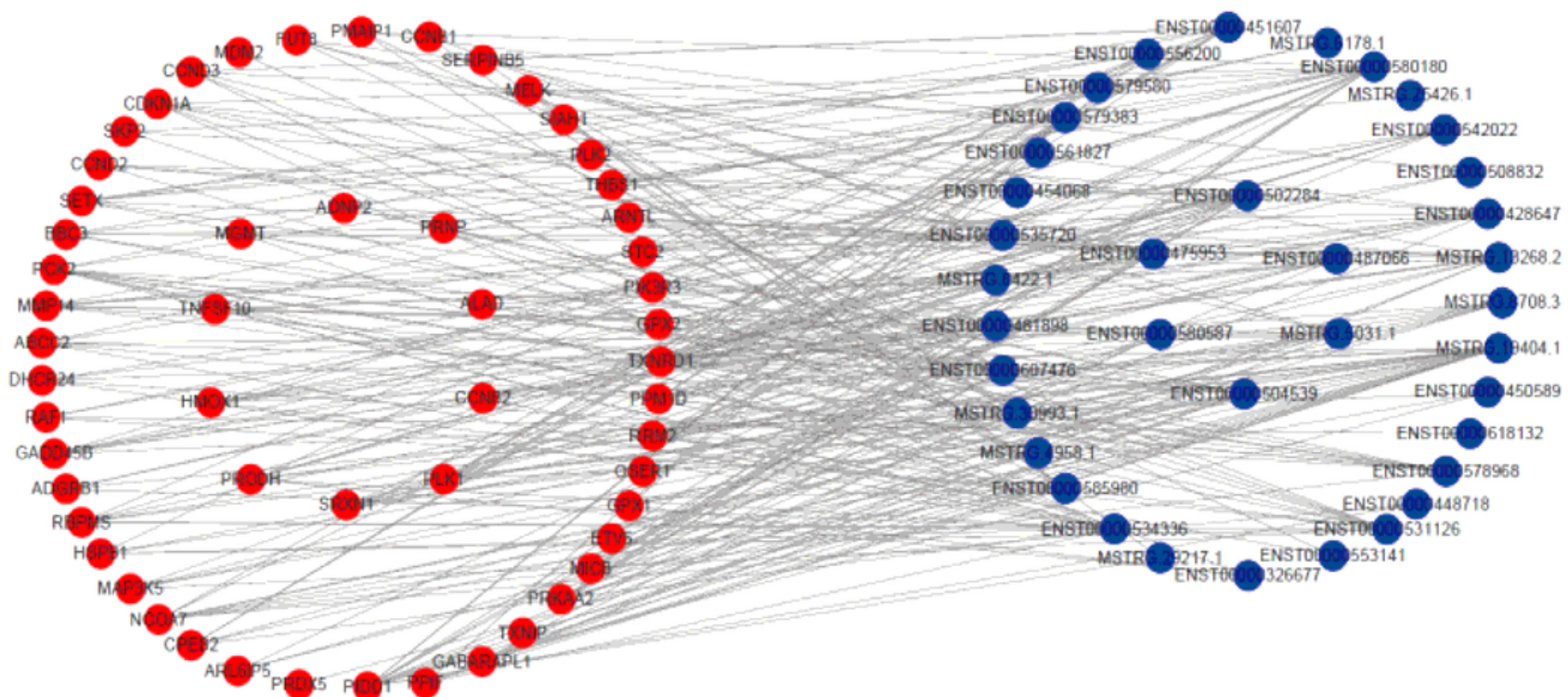

B

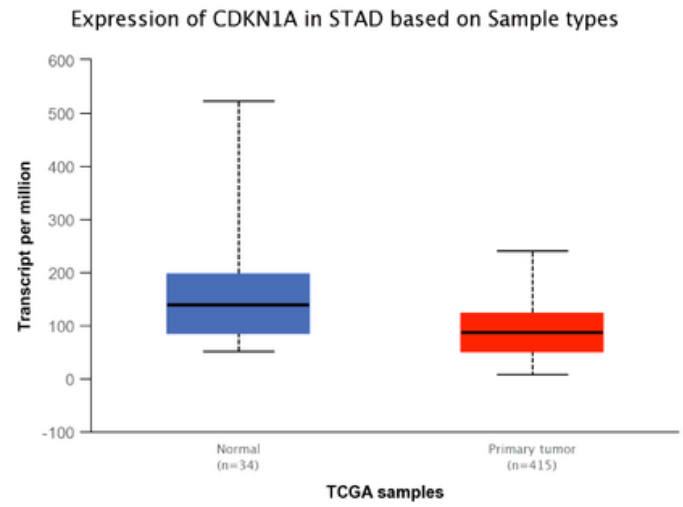

$\mathrm{C}$

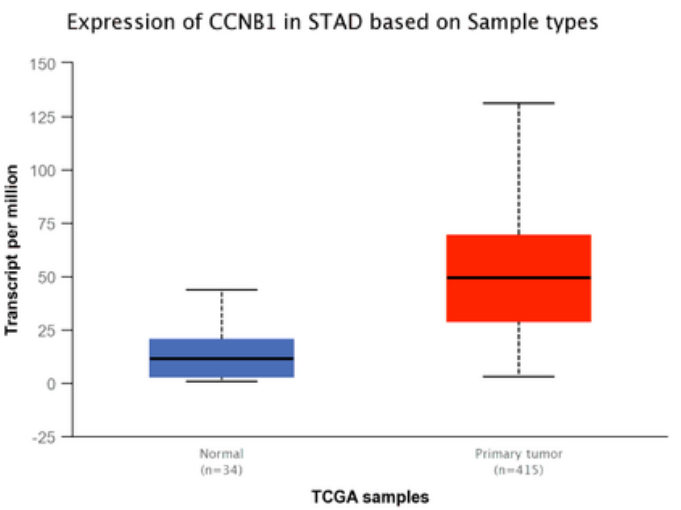

D

Expression of MAP3K5 in STAD based on Sample types

$\mathrm{E}$
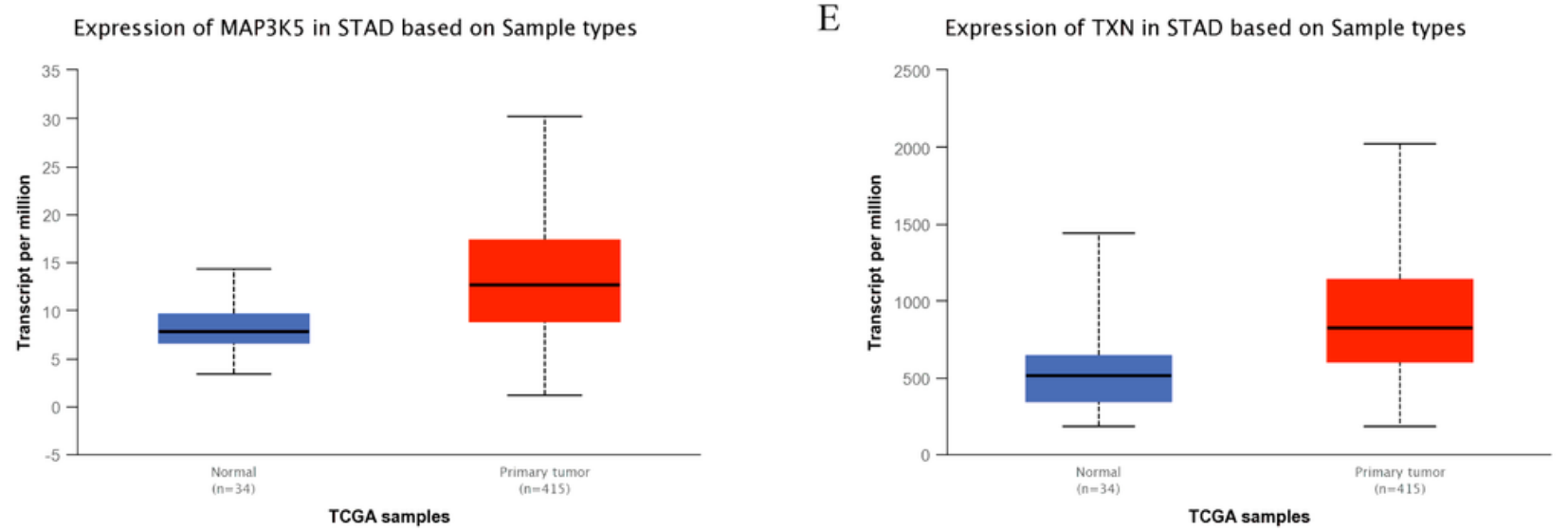

Figure 6

(A) Interaction of genes and IncRNAs related to oxidative stress. Expression of CDKN1A (B), CCNB1 (C), MAP3K5 (D) and TXN (E) in STAD based on TCGA samples (normal and primary tumors). 

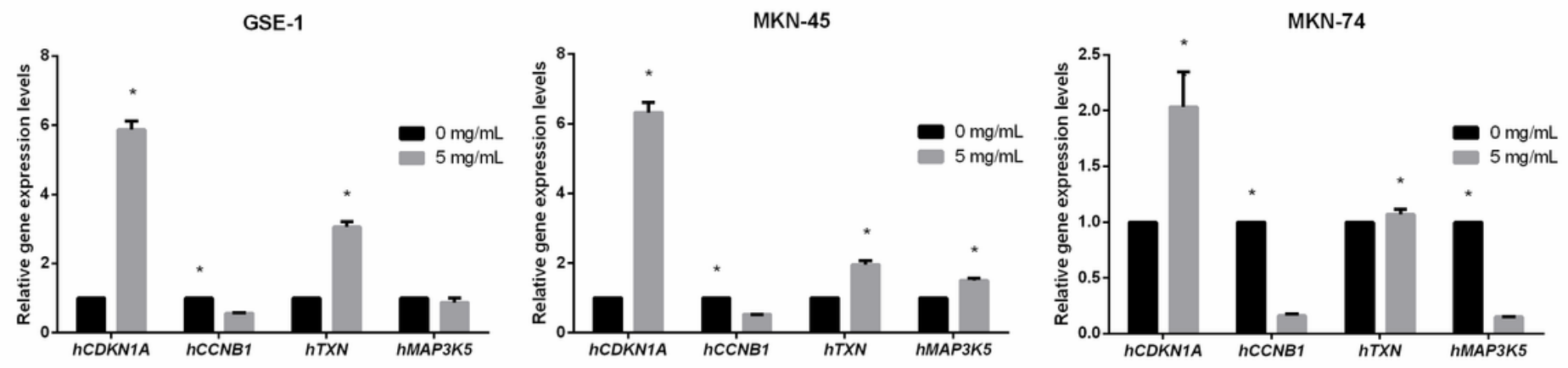

Figure 7

The relative hCDKN1A, hCCNB1, hTXN and hMAP3K5 gene expression levels after treatment with 5 $\mathrm{mg} / \mathrm{mL}$ ACBP-S-Se were detected by RT-PCR. ACBP-S-Se $(0 \mathrm{mg} / \mathrm{mL})$ was used as the control group. *, represents $\mathrm{P}<0.05$ compared with the control group. 


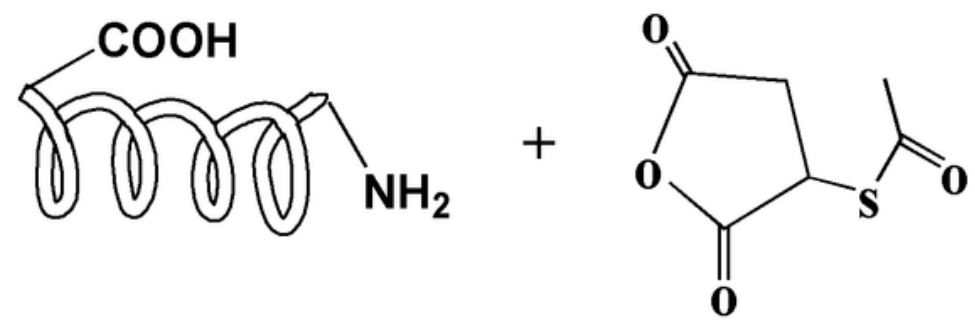

ACBP

S-SAMS
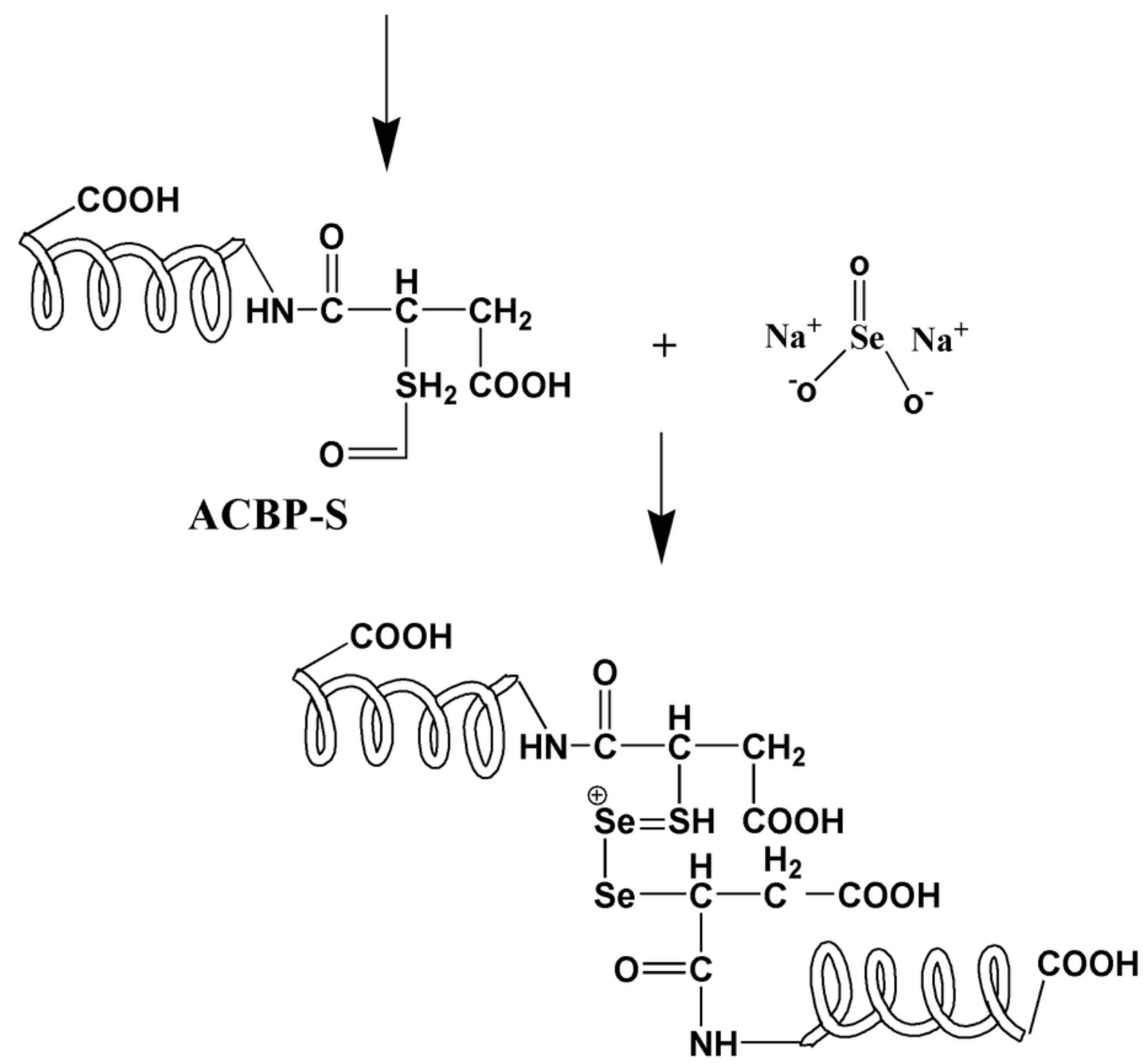

ACBP-S-Se

Figure 8

Mechanism of the synthesis of ACBP, S-SAMS and sodium selenite. First, ACBP was submitted to sulfhydrylation modification by S-AMSA and then participated in chelation reactions with sodium selenite. 